\title{
Deep Dive Identification and Evaluation of Critical Factors Responsible for Poor Routine Immunization Uptake in Oyo State
}

\author{
Bassey Enya Bassey, Fiona Braka, Sisay Gashu Tegene, Kofi Boateng, Rosemary Onyibe, \\ Olufunmilola Olawumi Kolude, Marion Mosunmola Osanoto, Leonard Idemudia Ugheighele, \\ Ayomide Oluwaseyi Aibinuomo, Joy Ogechi Max-ikechebelu, Olayiwola Suliat Olanike, \\ Angela Ugochukwu Okocha-ejeko
}

World Health Organization, Country Representative Office, Abuja, Nigeria

Email address:

Bassey69@yahoo.com (B. E. Bassey)

\section{To cite this article:}

Bassey Enya Bassey, Fiona Braka, Sisay Gashu Tegene, Kofi Boateng, Rosemary Onyibe, Olufunmilola Olawumi Kolude, Marion Mosunmola Osanoto, Leonard Idemudia Ugheighele, Ayomide Oluwaseyi Aibinuomo, Joy Ogechi Max-ikechebelu, Olayiwola Suliat Olanike, Angela Ugochukwu Okocha-ejeko. Deep Dive Identification and Evaluation of Critical Factors Responsible for Poor Routine Immunization Uptake in Oyo State. Science Journal of Public Health. Vol. 9, No. 3, 2021, pp. 77-82. doi: 10.11648/j.sjph.20210903.12

Received: March 16, 2021; Accepted: March 29, 2021; Published: May 15, 2021

\begin{abstract}
The uptake of Routine immunization services continues to decline in Oyo State despite best efforts to improve Routine Immunization (RI) services. This study aims to investigate the root cause of poor routine immunization uptake in the State using Ibadan north and Kajola Local Government Areas (LGAs) as sentinel study sites in Oyo state, Nigeria. A crosssectional Community survey was conducted between $26^{\text {th }}-30^{\text {th }}$ November 2018 using structured questionnaires uploaded onto Open Data Kit-collect (ODK) mobile software in the 2 LGAs namely Kajola and Ibadan North LGAs, Oyo state. Majority of the respondents Local Immunization Officers, RI Focal Persons, Other Health Workers and Community Members were fully aware of RI services, its benefits/importance and were mostly satisfied with the services they received at their community health facility. However, $95 \%$ of the respondents stated that they were not part of the RI planning processes in their communities neither were they actively involved in selecting the date, time or venue for RI in their communities. Also $76 \%$ of the respondents stated that Health workers neither rescheduled RI sessions for missed children neither did they visit /track the missed children. Functional Village Development Committees (VDCs) and updated Reaching Every Ward (REW) micro-plan was not present in $67 \%$ and $62 \%$ of the visited facilities respectively. World Health Organization (WHO) was mostly responsible for funding of immunization activities. Funding and poor engagement with members of the communities have been discovered to be a major contributing factor to poor immunization uptake in these LGAs. We advise that this gap be bridged for the purposes of improved RI uptake in the state.
\end{abstract}

Keywords: Routine Immunization, Unimmunized Children, Vaccination Coverage, Immunization Uptake

\section{Introduction}

Childhood immunization is regarded as an important indicator of a healthy childhood because it assures the protection from major childhood diseases. [1]. Besides being cost effective, the routine immunization (RI) of children is by far the most successful public health interventions that have considerably reduced global childhood morbidity and mortality rates. [2, 3].

In 1974, World Health Organization (WHO) launched the
Expanded Program on Immunization (EPI) aimed at controlling six-childhood diseases namely: tuberculosis, diphtheria, pertussis (whooping cough), tetanus, poliomyelitis and measles [4]. Currently, Nigeria's EPI aims to immunize all children between the ages of 0 and 23 months against eight vaccine-preventable diseases, which include, in addition to the above-mentioned diseases, hepatitis B (introduced in 2002) and Hemophilus influenza type b (introduced in 2008) $[5,6]$. Guidelines states that one child should receive four doses of Oral Polio Vaccine (OPV), 
three doses of Hepatitis B, Diphtheria, pertussis, tetanus and Haemophilus influenza type $b$ vaccines, and one dose each of measles, Baccile Calmette-Guerin (BCG) and yellow fever vaccines by the age of one (year) [7].

However, there continues to be a global decline in the uptake of RI despite efforts to improve immunization services. Annually, an estimated 18.7 million children under 1 year do not receive basic vaccination worldwide [8]. Consequently, millions of children die from vaccinepreventable diseases $[9,10]$.

In October 2018, the RI coverage for Oyo State, Nigeria was $82 \%$ for BCG and $85 \%$ for the third dose of the pentavalent vaccine (Penta 3), which serves the measure for RI coverage in the country. This was lower than the expected national coverage of $90 \%$ set by the Global Vaccine Action Plan (GVAP) launched by WHO to increase global vaccination coverage by 2020 [11].

The number of unimmunized children reported for the same month of October was 38,679. Reports following data analyses identified 14 Local Government Areas (LGAs) with highest number of unimmunized children. These LGAs contributed immensely to the suboptimal immunization coverage of less than $90 \%$ recorded in the state. Upon further analyses, two LGAs (Ibadan north and Kajola) were identified as LGAs with the highest number of unimmunized children, indicating a very poor level of immunization uptake. This study therefore aims to investigate the root cause of poor routine immunization coverage in these LGAs and identify possible solutions that should help improve the RI coverage of the state in general.

\section{Methods}

\section{Study Location}

This study was carried out in Oyo State. The state is one of the six states in the Southwest geopolitical zone of Nigeria. The State has a total projected population of $8,351,831$ people in 2018 from the 2006 census with annual target populations of $1,670,366$ (children under 5 years) and 334,073 (Under 1 year). Oyo state comprises 33 Local Government Areas (LGAs) with Ibadan north and Kajola being the LGAs of focus in this study.
Ibadan north and Kajola LGAs has 49 and 20 Health facilities respectively but only 32 and 17 of the health facilities respectively conduct RI activities.

\section{Study population}

Study population included 181 (130 from Ibadan south, 51 from Kajola) caregivers and 13 Health facilities/health workers ( 9 from Ibadan south, 4 from Kajola) in the LGAs. Total study population, $\mathrm{n}=194$.

\section{Study design}

A cross-sectional survey was conducted between $26^{\text {th }}-30^{\text {th }}$ November 2018 using structured questionnaires uploaded onto Open Data Kit-collect (ODK) mobile software in the 2 LGAs in Oyo state.

Three questionnaires were developed for the purposes of this study. The questionnaires were administered to the health workers at the health facility level (one heath worker per facility) and the respondents at the community/household level.

\section{Inclusion and exclusion criteria}

Ibadan north and Kajola were selected based on their high rates of unimmunized children. On the average, $23 \%$ of the health facilities conducting Routine Immunization were randomly selected within the above listed LGAs. At the selected health facilities, $30 \%$ of the catchment settlements were randomly selected. Five (5) households were selected from each settlement using simple random or systematic sampling methods.

\section{Ethical consideration}

A written permission was obtained from the Ministry of Health, Oyo State, and verbal/oral approval of the study participants (parent/caregiver) were obtained prior to data collection.

\section{Data Collection tools and techniques}

The standardized questionnaires were used for face-to-face interviews in the communities and at the health facilities. Responses were collected in real-time using Online Data Kit (ODK) with the assistance of a research assistant.

\section{Data analysis/Reliability and Validity of Data}

Geospatial analyses were conducted to know the exact location of the health facilities and location of respondents. Cross tabulation was used to check interference of socio demographic variables across the dependent variables.

\section{Results}

Table 1. Household Awareness on Routine Immunization services in the Community settings.

\begin{tabular}{|c|c|c|}
\hline Variables & Yes $(\%)$ & No $(\%)$ \\
\hline Are you aware of RI Services in your community $(n=181)$ & $177(98)$ & $4(2)$ \\
\hline Are you aware of the location of health facility that offers RI $(n=181)$ & $175(97)$ & $6(3)$ \\
\hline Do you know the benefits of Routine Immunization $(n=181)$ & $172(95)$ & $9(5)$ \\
\hline Are you satisfied with the Immunization services in the Community $(n=181)$ & $172(95)$ & $9(5)$ \\
\hline Do you know any Anti Immunization/ campaigner in your community (181) & $18(10)$ & $163(90)$ \\
\hline Do you have a vaccination card where your child name is written $(n=181)$ & $158(87)$ & $23(13)$ \\
\hline Has there been a planning meeting on Routine Immunization in your community you are aware of $(n=181)$ & $59(33)$ & $122(67)$ \\
\hline If yes, Did the community select Date, Venue and time for RI? $(n=181)$ & $62(44)$ & $119(66)$ \\
\hline Do health workers gives notification before coming for RI in your community $(n=181)$ & $112(62)$ & $69(38)$ \\
\hline Do health workers reschedule RI sessions if missed for any reason $(n=181)$ & $43(24)$ & $138(76)$ \\
\hline Do health worker visit if child misses date of appointment $(n=181)$ & $43(24)$ & $128(76)$ \\
\hline
\end{tabular}


Table 2. Knowledge of Health workers on Routine Immunization Services.

\begin{tabular}{|c|c|c|}
\hline Variables & Yes $(\%)$ & No (\%) \\
\hline Does the Health worker reside in this community $(n=13)$ & $3(23)$ & $10(77)$ \\
\hline Has Heath worker been trained on Routine Immunization in the past 1 year $(n=13)$ & $10(77)$ & $3(23)$ \\
\hline Does the Health Worker knows the 6 key messages on immunization passed on to caregivers on immunization days ( $\mathrm{n}=13$ ) & $12(92)$ & $1(8)$ \\
\hline Does the community/representatives of the community take part in REW Micro-planning for immunization purposes ( $\mathrm{n}=13$ ) & $7(54)$ & $6(46)$ \\
\hline Does the health facility receive funds for immunization $(n=13)$ & $9(69)$ & $4(31)$ \\
\hline Source of Funding (Multiple response) (yes $=$ WHO, no= LGA, n=9) & $8(89)$ & $1(11)$ \\
\hline Does the health facility have vaccine stock out of any antigen $(n=13)$ & $0(0)$ & $13(100)$ \\
\hline Is there a functional Village Development Committee $(n=13)$ & $9(69)$ & $4(31)$ \\
\hline If yes, Evidence of Minute of Meeting ( $n=9)$ & $3(33)$ & $6(67)$ \\
\hline Is there a Defaulter tracking mechanism in the health facility $(n=13)$ & $8(62)$ & $5(39)$ \\
\hline Does the health facility have a functional Megaphone to announce immunization activities ( $\mathrm{n}=13$ ) & $6(42)$ & $7(54)$ \\
\hline Does the health facility have an updated REW micro-plan $(n=13)$ & $5(39)$ & $8(62)$ \\
\hline Does the health facility have Session Plan on display $(n=13)$ & $5(39)$ & $8(62)$ \\
\hline Does the health facility have a Monitoring chart $(n=13)$ & $11(85)$ & $2(15)$ \\
\hline If yes, Do they understand the chart and use the information for action $(n=11)$ & $7(54)$ & $4(31)$ \\
\hline Is the data in the health facility properly archived in the health facility $(n=13)$ & $11(85)$ & $2(15)$ \\
\hline If yes, are the records in the last six months seen in the health facility $(\mathrm{n}=11)$ & $9(69)$ & $2(15)$ \\
\hline Does the Health Facility analyze data by settlement and used for action $(n=13)$ & $4(31)$ & $9(69)$ \\
\hline
\end{tabular}

Table 3. Effects of socio-demographic factors on Routine Immunization uptake in the LGAs.

\begin{tabular}{|c|c|c|c|c|c|}
\hline Socio-economic Factors & Not immunized (\%) & Fully Immunized (\%) & Partially immunized (\%) & Total & P value \\
\hline \multicolumn{6}{|l|}{ Type of Settlement } \\
\hline Urban & $37(42.5)$ & $48(55.2)$ & $2(2.3)$ & $87(100)$ & \multirow{5}{*}{0.345} \\
\hline Rural & $13(28.3)$ & $31(67.4)$ & $2(4.3)$ & $46(100)$ & \\
\hline Semi-Urban & $19(44.2)$ & $23(53.5)$ & $1(2.3)$ & $43(100)$ & \\
\hline Isolated/Village & $4(80.0)$ & $1(20.0)$ & $0(0.0)$ & $5(100.0)$ & \\
\hline \multicolumn{5}{|l|}{ Highest Level of Education } & \\
\hline No formal education & $11(57.9)$ & $7(36.8)$ & $1(5.3)$ & $19(100.0)$ & \multirow{4}{*}{0.280} \\
\hline Primary Education & $19(51.4)$ & $16(43.2)$ & $2(5.4)$ & $37(100.0)$ & \\
\hline Secondary Education & $38(39.2)$ & $57(58.8)$ & $2(2.1)$ & $97(100.0)$ & \\
\hline Tertiary Education & $5(17.9)$ & $23(82.1)$ & $0(0.0)$ & $28(100.0)$ & \\
\hline \multicolumn{6}{|l|}{ Occupation of Respondent } \\
\hline None & $4(80.0)$ & $1(20.0)$ & $0(0.0)$ & $5(100.0)$ & \multirow{7}{*}{0.222} \\
\hline Trader & $37(42.0)$ & $49(55.7)$ & $2(2.3)$ & $88(100.0)$ & \\
\hline Artisan & $20(40.0)$ & $28(55.7)$ & $2(2.3)$ & $50(100.0)$ & \\
\hline Farming & $6(60.0)$ & $3(30.0)$ & $1(10.0)$ & $10(100.0)$ & \\
\hline Teaching & $3(33.3)$ & $6(66.7)$ & $0(0.0)$ & $9(100.0)$ & \\
\hline Housewife & $2(33.3)$ & $4(66.7)$ & $0(100.0)$ & $6(100.0)$ & \\
\hline Others & $1(7.7)$ & $12(92.3)$ & $0(0.0)$ & $13(100.0)$ & \\
\hline \multicolumn{6}{|l|}{ Household Size } \\
\hline $1-4$ & $24(33.3)$ & $47(65.3)$ & $1(1.4)$ & $72(100.0)$ & \multirow{2}{*}{0.154} \\
\hline 4 and above & $49(45.0)$ & $56(51.4)$ & $4(3.7)$ & $109(100.0)$ & \\
\hline
\end{tabular}

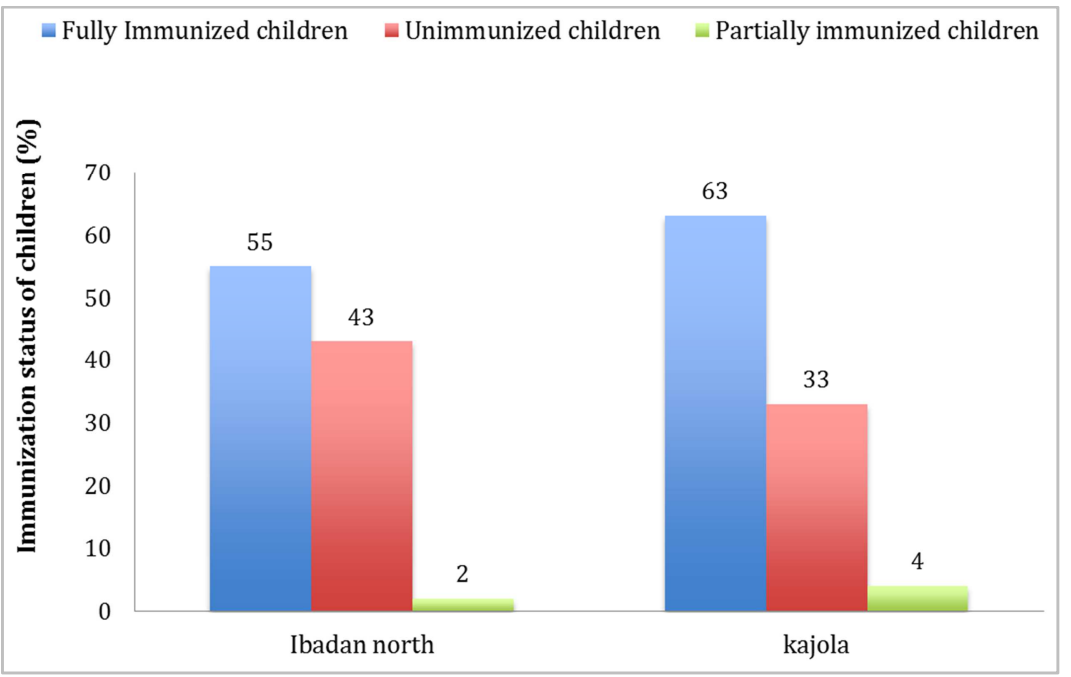

Figure 1. Routine Immunization status of children by $L G A$. 
The Routine Immunization status of the children of surveyed respondents was shown in figure 1 . There were 130 and 51 respondents from Ibadan north and Kajola LGA respectively with $89 \%$ of them being mothers. About $55 \%$ (Ibadan north) and $63 \%$ (Kajola) of the children were fully immunized while $43 \%$ and $33 \%$ of the children Ibadan north and Kajola LGAs respectively were unimmunized.

The level of awareness on Routine Immunization at the community level was accessed next as shown in table 1 . About $97 \%$ of the respondents knew about RI activities in their communities. They were also mostly aware of the location of the health facilities for RI purposes (97\%) and were mostly satisfied with the services rendered at the facilities (95\%). Also, 95\% of the respondents agreed that they were well informed on the benefits of RI.

However, $67 \%$ of the respondents were not involved in the RI planning process and were mostly not involved in picking out dates, location for RI in their communities. Although $62 \%$ of the respondents agreed that the health workers give prior notification of RI, they mostly don't reschedule missed sessions (76\%) and mostly don't visit or tract children who missed sessions $(76 \%)$.

Knowledge of health worker on RI was assessed as indicated in Table 2. At the health facility level, $77 \%$ of the health workers surveyed agreed to have had refresher training on RI done in the past year.

About $54 \%$ of the health workers had the community members involved in the Reaching Every Ward (REW) microplanning process for immunization activities while $46 \%$ did not. This REW micro-plan was also not updated by the health workers in $62 \%$ of the facilities. A village development committee was present in $69 \%$ of the communities but only $33 \%$ had the 'minutes of meeting' as evidence of functionality.

About $69 \%$ of the respondents agreed that their facilities received funding for RI activities with WHO being the major contributor $(89 \%)$. Defaulters tracking mechanisms were however in place in $62 \%$ of the facilities and there had never been a stock out of vaccines in the facilities.

The effects of certain socio-economic factors on the uptake of immunization in the communities were accessed in table 3 . Respondents in isolated villages had the highest rate of unimmunized $(83 \%)$ and the lowest rate of fully immunized children (20\%). The rural dwellers had the highest rate $(67 \%)$ of fully immunized and the lowest rate of unimmunized children.

Respondents with no formal education recorded the highest rate of unimmunized children and the least rate of fully immunized children while respondents with tertiary education recorded the least level of unimmunised children and the highest rate of fully immunized children.

Respondents with no occupation had the highest rate of unimmunized children and the least rate of fully immunized children while respondents with other forms of education not captured in this survey recorded the highest rate of fully immunized children and the least rate of unimmunized children.

Respondents in households with more than 4 people had the highest rate of unimmunized children while households with 1-
4 people had the highest number of fully immunized children.

\section{Discussion}

Reasons for poor immunization uptake and coverage have mostly been attributed to certain maternal aspects (e.g. knowledge on RI with particular emphasis of timing of the next due vaccination date, distance travelled to health facility and even attitude of health workers) by several studies $[12,13]$ However, not much attention has been paid to the factors at the health facilities/health services/community interface and how those factors influence RI behaviour either by facilitating or hampering it. This study deep dives into the root cause of poor RI uptake in 2 LGAs (Ibadan north and Kajola) with the highest number of unimmunized children in Oyo state, Nigeria.

About $89 \%$ of the respondents in this study were mothers. Majority of these mothers were also fully aware of RI services, its benefits/importance and were even mostly satisfied with the services they received at their community health facility. This agrees with similar studies carried out in Ibadan and Edo state where only 3\% of the mothers knew nothing of RI $[14,15]$.

However, 95\% of the respondents according to our results stated that they were not carried along or part of the RI planning processes in their communities neither were they actively involved in selecting the date, time or venue for RI in their communities, even though health workers majorly gave prior notice before coming for RI. Also $76 \%$ of the respondents stated that Health workers neither rescheduled RI sessions for missed children neither did they visit /track the missed children.

Though some of these problems could be attributed to short staffing or the fact that majority of the health workers did not reside in the communities, which they work especially as it concerns defaulters visits and rescheduling of RI sessions as per our results, we believe that the major problem and solution largely depends on the functionality of the Village Development Committees (VDC) and the effectiveness of the Reaching Every Ward (REW) microplanning for RI activities [16].

The idea behind the establishment of VDCs was to create a forum where community members and the health workers meet regularly to discuss all things RI for the purposes of improving RI services. During a focus group discussion with the respondents after the survey, the respondents talked about, seized vaccination cards by a health worker because fees charged for RI could not be paid, some also complained that the health workers would not open new BCG vials for vaccination because there were few children and didn't want to waste the vaccine, some others talked about the fear of health workers aggression towards them whenever they forget their next due date. These are issues that could have been discussed and resolved with clear recommendations if there were functional VDCs. RI services are free and WHO would rather have one child immunized as against sending that child away in anticipation of a more reasonable number, as there are no guarantees of the child's return. Issues likes 
these would have been captured in the minutes of the meetings and would have attracted prompt action from WHO staff/DSNOs during their weekly supervisory visits.

From all these, it is obvious that a breach in communication between the community and health facilities has contributed its fair share to the problem of missed immunization sessions.

On the flip side, health workers in the facilities suggested that the non-functionality of their VDCs could be attributed to poor participation of community members' because funds were not available to host or support such meetings. The burden of funding of RI services was majorly borne by WHO both in this study and several other studies carried out in Edo, Kebbi and indeed across Nigeria with little input coming from the state or LGA, despite RI being the major responsibility of the Government [17]. We believe that the provision of more funds for immunizations activities by the Government would create room for sustainable subventions to be allocated for these meetings. This would encourage participation, bridge communication/planning gaps and ultimately improve RI uptake in the communities.

WHO guidelines on RI planning activities that basic information about communities must first be collected before an effective health intervention plan can be made [18]. The REW micro-planning process embodies this recommendation as it includes information of the communities down to the ward unit (the smallest administrative unit in the country) and as such must be done in collaboration with members of communities and constantly updated to accommodate the changes in the communities. However, our results indicate a 54\%: 46\% ratio in the participation of the communities while $62 \%$ of the facilities didn't have their REW micro-plans updated. It is difficult to effectively plan and cater for a community with incorrect information. We believe this also majorly explains why $76 \%$ of the respondents whose children missed immunization sessions weren't visited or tracked by the health workers even when $62 \%$ of the facilities claim to have defaulter tracking mechanisms in place and cite non-availability of funds as reasons why it might not be fully effective. Therefore, we recommend that health facilities constantly update their REW micro-plan and effectively rapport and collaborate with their hosting communities towards achieving best results from RI.

Effects of certain socio-demographic factors such type of settlement (rural or urban), occupation, level of formal education and household size on RI uptake were also analysed. Our results indicated respondents in urban areas had the least number unimmunized/partially immunized children in comparison to their rural/isolated village counterpart. Though with a pvalue $>0.05$, it might not be of statistical significance. A study done in Ogun state, Nigeria correlates this by stating in its findings that location or type settlement was not a predictor of immunisation status [19]. Also, respondents with secondary school or tertiary education had the least number of unimmunized children in comparison to their counterparts with no education. This agrees with another study in Ibadan where levels of education affected immunization status but with a pvalue $>0.05$ as in both studies, it might not be considered as a major predictor of immunization status [20]. Even though these demographic factors were strongly associated with immunization status a per our results, it is our believe that their effect might be due to confounding or intervening factors and there is need to further research into this.

\section{Conclusion}

Funding RI and poor systematic engagement with members of the communities have been discovered to be a major contributing factor to poor immunization uptake in these LGAs. We advise that the funding gap and weak community engagement should be bridged for the purposes of improved RI uptake in the state.

\section{Authors' Contributions}

OOK, MMO, BEB, LIO, and AOA, JMI, OSO, contributed to the study design, interpretation of results, and manuscript conceptualization and preparation. FB SGT, BF, $\mathrm{BEB}$, data management and interpretation, and manuscript conceptualization and preparation. BEB and AO contributed to the study design and manuscript preparation. All authors read and approved the final manuscript.

\section{Ethics Approval and Consent to Participate}

The consultation of an ethics committee and consent to participate is not required for analyses based solely on secondary data.

\section{Competing Interests}

The authors declare that they have no competing interests.

\section{Acknowledgements}

We wish to acknowledge the tireless and selfless effort of the personnel at the state and LGA levels; Omowele Adekumbi Fumilayo, Moshood Busari Babatunde, Ugba Faith, Olawuyi Abisola, Nsikak Udo, Aminu Rukayat Abisola, Rukayat Adenike Okanlawon, Iyamda Abdulateef.

\section{References}

[1] Ashok A, Brison M, LeTallec Y. Improving cold chain systems: Challenges and solutions. Vaccine [Internet]. 2017 Apr 19 [cited 2019 Jan 3]; 35 (17): 2217-23. Available from: http://www.ncbi.nlm.nih.gov/pubmed/27670076.

[2] Bekele AT, Fiona B, Thomas K, Kassahun A, Kathleen G, Nsubuga $P$, et al. Factors contributing to routine immunization performance in Ethiopia, 2014. Pan Afr Med J [Internet]. 2017 [cited 2019 Jan 3]; 27 (Suppl 2): 5. Available from: http://www.panafrican-medjournal.com/content/series/27/2/5/full/. 
[3] Bugvi AS, Rahat R, Zakar R, Zakar MZ, Fischer F, Nasrullah $\mathrm{M}$, et al. Factors associated with non-utilization of child immunization in Pakistan: evidence from the Demographic and Health Survey 2006-07. BMC Public Health [Internet]. 2014 Dec 6 [cited 2019 Jan 3]; 14 (1): 232. Available from: http://www.ncbi.nlm.nih.gov/pubmed/24602264.

[4] WHO | The Expanded Programme on Immunization. WHO [Internet]. 2013 [cited 2019 Jan 3]; Available from: https://www.who.int/immunization/programmes_systems/supp ly_chain/benefits_of_immunization/en/.

[5] Bassey BE, Vaz RG, Gasasira AN, Braka F, Weldegriebriel G, Komakech W, et al. Pattern of the meningococcal meningitis outbreak in Northern Nigeria, 2009. Int J Infect Dis [Internet]. 2016; 43: 62-7. Available from: http://linkinghub.elsevier.com/retrieve/pii/S120197121500297 0.

[6] LOWTHER SA, SHINODA N, JUNI BA, THEODORE MJ, WANG X, JAWAHIR SL, et al. Haemophilus influenzae type b infection, vaccination, and $\mathrm{H}$. influenzae carriage in children in Minnesota, 2008-2009. Epidemiol Infect [Internet]. 2012 Mar 18 [cited 2019 Jan 3]; 140 (03): 566-74. Available from: http://www.ncbi.nlm.nih.gov/pubmed/21676359.

[7] Ophori EA, Tula MY, Azih A V, Okojie R, Ikpo PE. Current trends of immunization in Nigeria: prospect and challenges. Trop Med Health [Internet]. 2014 Jun [cited 2017 Jul 10]; 42 (2): 67-75. Available from: http://www.ncbi.nlm.nih.gov/pubmed/25237283.

[8] Imran H, Raja D, Grassly NC, Wadood MZ, Safdar RM, O'Reilly KM. Routine immunization in Pakistan: comparison of multiple data sources and identification of factors associated with vaccination. Int Health [Internet]. 2018 Mar 1 [cited 2019 Jan 3]; 10 (2): 84-91. Available from: https://academic.oup.com/inthealth/article/10/2/84/4843994.

[9] Jani J V, De Schacht C, Jani I V, Bjune G. Risk factors for incomplete vaccination and missed opportunity for immunization in rural Mozambique. 2008 [cited 2019 Jan 3]; Available from: http://www.biomedcentral.com/14712458/8/161.

[10] Duclos P, Okwo-Bele J-M, Gacic-Dobo M, Cherian T. Global immunization: status, progress, challenges and future. BMC Int Health Hum Rights [Internet]. 2009 Oct 14 [cited 2019 Jan 3]; 9 Suppl 1 (Suppl 1): S2. Available from: http://www.ncbi.nlm.nih.gov/pubmed/19828060.

[11] WHO | Immunization coverage reaches 84\%, still short of $90 \%$ goal. WHO [Internet]. 2014 [cited 2019 Jan 3]; Available from: https://www.who.int/immunization/newsroom/press/immuniza tion_coverage_july2014/en/.

[12] Khan MU, Ahmad A, Aqeel T, Salman S, Ibrahim Q, Idrees J, et al. Knowledge, attitudes and perceptions towards polio immunization among residents of two highly affected regions of Pakistan. BMC Public Health [Internet]. 2015 Dec 5 [cited 2019 Jan 3]; 15 (1): 1100. Available from: http://www.ncbi.nlm.nih.gov/pubmed/26541976.

[13] LaFond A, Kanagat N, Steinglass R, Fields R, Sequeira J, Mookherji S. Drivers of routine immunization coverage improvement in Africa: findings from district-level case studies. Health Policy Plan [Internet]. 2015 Apr 1 [cited 2019 Jan 3]; $30 \quad$ (3): 298-308. Available from: https://academic.oup.com/heapol/articlelookup/doi/10.1093/heapol/czu011.

[14] Adokiya MN, Baguune B, Ndago JA. Evaluation of immunization coverage and its associated factors among children 12-23 months of age in Techiman Municipality, Ghana, 2016. Arch Public Health [Internet]. 2017 [cited 2019 Jan 3]; 75: 28. Available from: http://www.ncbi.nlm.nih.gov/pubmed/28652913.

[15] Owais A, Hanif B, Siddiqui AR, Agha A, Zaidi AKM. Does improving maternal knowledge of vaccines impact infant immunization rates? A community-based randomizedcontrolled trial in Karachi, Pakistan. BMC Public Health [Internet]. 2011 Apr 17 [cited 2019 Jan 3]; 11: 239. Available from: http://www.ncbi.nlm.nih.gov/pubmed/21496343.

[16] Favin M, Steinglass R, Fields R, Banerjee K, Sawhney M. Why children are not vaccinated: a review of the grey literature. Int Health [Internet]. 2012 Dec 1 [cited 2019 Jan 3]; 4 (4): 229-38. Available from: https://www.sciencedirect.com/science/article/pii/S187634131 2000496.

[17] Faniyan O, Opara C, Oyinade A, Botchway P, Soyemi K. Vaccine financing in Nigeria: are we making progress towards self-financing/sustenance? Pan Afr Med J [Internet]. 2017 [cited 2019 Jan 3]; 27. Available from: http://www.panafricanmed-journal.com/content/series/27/3/9/full/.

[18] $\mathrm{WHO} \mid \mathrm{WHO}$ recommendations for routine immunization summary tables. WHO [Internet]. 2018 [cited 2019 Jan 3]; Available from: https://www.who.int/immunization/policy/immunization table s/en/.

[19] Ijarotimi IT, Fatiregun AA, Adebiyi OA, Ilesanmi OS, Ajumobi O. Urban-rural differences in immunisation status and associated demographic factors among children 12-59 months in a southwestern state, Nigeria. Uthman O, editor. PLoS One [Internet]. 2018 Nov 5 [cited 2019 Jan 3]; 13 (11): e0206086. Available from: http://dx.plos.org/10.1371/journal.pone.0206086.

[20] Adenike O-B, Adejumoke J, Olufunmi O, Ridwan O. Maternal characteristics and immunization status of children in North Central of Nigeria. Pan Afr Med J [Internet]. 2017 [cited 2019 Jan 3]; 26. Available from: http://www.panafricanmed-journal.com/content/article/26/159/full/. 